\title{
Reference right atrial dimensions and volume estimation by steady state free precession cardiovascular magnetic resonance
}

\author{
Alicia M Maceira', Juan Cosín-Sales ${ }^{2}$, Michael Roughton $^{3}$, Sanjay K Prasad ${ }^{4}$ and Dudley J Pennell ${ }^{4^{*}}$
}

\begin{abstract}
Background: Cardiovascular magnetic resonance (CMR) steady state free precession (SSFP) cine sequences with high temporal resolution and improved post-processing can accurately measure RA dimensions. We used this technique to define ranges for normal RA volumes and dimensions normalized, when necessary, to the influence of gender, body surface area (BSA) and age, and also to define the best 2D images-derived predictors of RA enlargement.

Methods: For definition of normal ranges of RA volume we studied 120 healthy subjects (60 men, 60 women; 20 subjects per age decile from 20 to 80 years), after careful exclusion of cardiovascular abnormality. We also studied 120 patients (60 men, 60 women; age range 20 to 80 years) with a clinical indication for CMR in order to define the best 1D and 2D predictors of RA enlargement. Data were generated from SSFP cine CMR, with 3-dimensional modeling, including tracking of the atrioventricular ring motion and time-volume curves analysis.

Results: In the group of healthy individuals, age influenced RA 2-chamber area and transverse diameter. Gender influenced most absolute RA dimensions and volume. Interestingly, right atrial volumes did not change with age and gender when indexed to body surface area. New CMR normal ranges for RA dimensions were modeled and displayed for clinical use with normalization for BSA and gender and display of parameter variation with age. Finally, the best 2D images-derived independent predictors of RA enlargement were indexed area and indexed longitudinal diameter in the 2-chamber view.
\end{abstract}

Conclusion: Reference RA dimensions and predictors of RA enlargement are provided using state-of-the-art CMR techniques.

Keywords: Magnetic resonance, Heart, Right atrial volume, Dimensions, Reference values

\section{Background}

Right atrial (RA) enlargement may occur in numerous conditions including congenital heart disease, acquired valvular disease, pulmonary disorders, and heart failure. Remodeling of the RA has also been reported in patients with paroxysmal atrial fibrillation (AF) [1-3], and recent data have shown that both left atrial (LA) and RA remodeling are equally associated with recurrence of $\mathrm{AF}$ after cardioversion [4]. Interestingly, RA and LA remodeling may coexist because one predisposes the heart to

\footnotetext{
* Correspondence: d.pennell@ic.ac.uk

${ }^{4}$ Cardiovascular Magnetic Resonance Unit, Royal Brompton Hospital, Sydney Street, London SW3 6NP, United Kingdom

Full list of author information is available at the end of the article
}

the other, so their combined enlargement may better express more remarkable structural remodeling and, more importantly, the combination of these conditions might be a better prognostic indicator of AF recurrence than either alone. Another potential clinical value of RA measurement, since RA size is at least partially determined by the same factors that affect diastolic right ventricular (RV) filling, is its ability to act as an early marker of RV dysfunction, which often precedes systolic dysfunction in a variety of conditions affecting the RV. Furthermore, it may provide significant prognostic information in patients with chronic systolic heart failure [5] and pulmonary hypertension $[6,7]$.

\section{Biomed Central}

(c) 2013 Maceira et al.; licensee BioMed Central Ltd. This is an Open Access article distributed under the terms of the Creative Commons Attribution License (http://creativecommons.org/licenses/by/2.0), which permits unrestricted use, distribution, and reproduction in any medium, provided the original work is properly cited. 
Atrial remodeling is most accurately estimated by measuring atrial volume, but in current clinical practice this is not routinely performed. Cardiovascular magnetic resonance (CMR) is the gold standard technique for measurement of ventricular dimensions and function with reference ranges established from the Steady State Free Precession (SSFP) technique [8,9], and this has also been reported for the left atrium [10]. Some studies on RA reference values have been published [11-13], but RA dimensions have not been extensively studied with CMR as well as the systematic analysis of the influences of age, gender and body surface area (BSA). Therefore, the aim of this study was to establish SSFP based reference values in normal subjects for RA dimensions normalized for independent influences such as gender, body surface area and age when required. We also aimed to determine the best predictors of right atrial enlargement among $1 \mathrm{D}$ and $2 \mathrm{D}$ parameters, and relate RA volume to RA diameters and areas, as these are easily obtained in the clinical setting.

\section{Methods}

Normals and patients

For definition of normal ranges of RA dimensions we studied 120 subjects, with 10 men and 10 women in each of 6 age deciles from 20 to 80 years. This cohort of healthy subjects has been used for defining left and right ventricular and LA reference dimensions. Their baseline characteristics have been published previously [8]. In brief, all subjects were normotensives (hypertension defined as systolic blood pressure $\geq 140 \mathrm{mmHg}$ and/or diastolic blood pressure $\geq 90 \mathrm{mmHg}$ ), asymptomatic, with no known risk factors or history of cardiac disease, and with normal physical examination and electrocardiogram (ECG). Height, weight, blood pressure, total cholesterol, HDL and B-natriuretic peptide were measured in all. BSA was calculated according to the Mosteller formula [14]. The coronary artery disease risk over 10 years was calculated [15]. BNP levels were $2.5 \pm 2.1 \mathrm{pg} / \mathrm{mL}$ (range $0.5-12.0)$, and all were in the normal range $(<100 \mathrm{pg} /$ $\mathrm{mL}$ ) [16]. Therefore, as far as it was possible to ascertain with conventional noninvasive techniques, all the apparently healthy volunteers had a normal cardiovascular system with no high blood pressure and no evidence of heart failure. In a second step, and in order to define the best $1 \mathrm{D}$ and $2 \mathrm{D}$ predictors of RA enlargement, a group of 120 patients (60 men and 60 women, age range 2080) that were referred to CMR for clinical reasons, who were in sinus rhythm and who agreed to participate in the study, were included. The main reasons for referral to CMR have been published elsewhere [10] and are briefly summarized in Table 1 . Research was in compliance with the Helsinki Declaration. The study was approved by the institutional Ethics Committee of the
Royal Brompton Hospital, and all subjects gave written informed consent.

\section{CMR}

CMR was performed with $1.5 \mathrm{~T}$ scanners (Siemens Sonata and Avanto) using front and back surface coils and retrospective ECG triggering for capture of the entire cardiac cycle including diastole. All CMR scans were performed by the same operator. SSFP end-expiratory breath-hold cines were acquired in the two (left and right chambers) and four chamber views, with subsequent contiguous short-axis cines from the atrioventricular (AV) ring to the base of the atria. Slice thickness was $5 \mathrm{~mm}$ with no gap between slices. The temporal resolution was $21 \pm 1 \mathrm{~ms}$. Sequence parameters included repetition time/echo time of $3.2 / 1.6 \mathrm{~ms}$, in-plane pixel size of $2.1 \times 1.3 \mathrm{~mm}$, flip angle $60^{\circ}$, and acquisition time of typically 18 heartbeats.

\section{CMR analysis}

Analysis was performed with a personal computer and semi-automated software (CMRtools, Cardiovascular Imaging Solutions, London, UK). In all subjects (healthy controls and patients) RA maximum volume was measured as well as maximum diameters and areas, measured in the 42-chamber and right 2-chamber views. Atrial volume analysis included 2 steps: First, delineation of the atrial endocardial border in all planes in all cardiac phases. Second, the systolic descent and twist of the tricuspid valve was calculated from tracking of the valve motion on the long axis cines, and used to correct for increase in atrial volume due to AV ring descent (Figure 1). We included the atrial appendage and excluded the cava veins. Other approaches are possible, but the arguments for and against are not decisive. All diameters and areas derived from $2 \mathrm{D}$ images were measured in the phase of the corresponding cine sequences at which the atrial size and volume measurements were at a maximum. The longitudinal diameter was measured form the midpoint of the line between the lateral and septal (or superior and inferior in the 2-chamber view) insertion of the tricuspid valve to the roof of the right atrium. Transverse diameter was measured perpendicular to the midpoint of the longitudinal diameter (Figure 2).

\section{Statistical analysis}

This was carried out with the statistical software SPSS Statistics 17.0 (IBM, United States). All atrial parameters were found to satisfy a normal distribution using the Kolmogorov-Smirnov test and summary data for these variables are presented as mean \pm SD. Intra and interobserver reproducibility were tested in 50 subjects belonging to the cohort of healthy subjects. Simple linear 
Table 1 Baseline characteristics of the healthy subjects and the patient group (mean \pm SD)

\begin{tabular}{|c|c|c|}
\hline & Healthy subjects & Patients \\
\hline $\mathrm{N}$ & 120 & 120 \\
\hline Males & $50 \%$ & $53 \%$ \\
\hline Age [yr] (min, max) & $49 \pm 17(20,80)$ & $65 \pm 12(20,80)$ \\
\hline Height $[\mathrm{cm}]$ & $171 \pm 9$ & $163 \pm 9$ \\
\hline Weight $[\mathrm{kg}]$ & $72 \pm 13$ & $76 \pm 13$ \\
\hline Body surface area $\left[\mathrm{m}^{2}\right]$ & $1.83 \pm 0.18$ & $1.82 \pm 0.18$ \\
\hline Body mass index $\left[\mathrm{kg} / \mathrm{m}^{2}\right]$ & $24 \pm 4$ & $29 \pm 5$ \\
\hline Heart Rate [bpm] & $66 \pm 10$ & $69 \pm 13$ \\
\hline Systolic blood pressure [mmHg] & $124 \pm 12$ & $140 \pm 25$ \\
\hline Diastolic blood pressure [mmHg] & $73 \pm 7$ & $77 \pm 14$ \\
\hline \multicolumn{3}{|l|}{ Pathology (n) } \\
\hline Ischemic heart disease & - & 46 \\
\hline Coronary risk factors & - & 35 \\
\hline Hypertensive heart disease & - & 12 \\
\hline Valvular heart disease & - & 13 \\
\hline Dilated cardiomyopathy & - & 4 \\
\hline Restrictive cardiomyopathy & - & 2 \\
\hline Congenital heart disease & - & 3 \\
\hline Myocarditis & - & 2 \\
\hline Hypertrophic cardiomyopathy & - & 1 \\
\hline Arrhythmogenic right ventricular cardiomyopathy & - & 1 \\
\hline Pericardial disease & - & 1 \\
\hline
\end{tabular}

regression was used to model the indexed data and to construct reference ranges as mean and 95\% confidence intervals. Multivariable analysis was used to analyze variations in parameters due to age and gender. $\mathrm{P}$ values $<0.05$ were considered significant. In the patient group, correlations of $1 \mathrm{D}$ and 2D parameters with RA volume were assessed with the Pearson's coefficient. Logistic regression analysis was used to define the best predictors of RA enlargement among 1D and 2D parameters. Linear regression analysis was used to develop a method to predict RA volume with these parameters.

\section{Results}

\section{Baseline characteristics and summary results for the healthy subjects group}

Table 1 summarizes the baseline characteristics of the healthy subjects included for defining normal reference values. The reproducibility study was undertaken by 2 operators with more than 5 years' experience in CMR. One operator assessed intraobserver variability and the other one, blinded to previous results, interobserver variability. Intraobserver variability [17] was 3.5\% for RA volume, $3.6 \%$ and $1.8 \%$ for areas in the 2-chamber and 4-chamber views, $4.1 \%$ and $4.2 \%$ for longitudinal and transverse diameters in the 2-chamber view, and $4.1 \%$ and $4 \%$ for longitudinal and transverse diameters in the 4-chamber view, respectively. Interobserver variability was $3.9 \%$ for RA volume, $5.2 \%$ and $5 \%$ for areas in the 2 chamber and 4-chamber views, $5.5 \%$ and $5.5 \%$ for longitudinal and transverse diameters in the 2-chamber view, and $5.8 \%$ and $5.1 \%$ for longitudinal and transverse diameters in the 4-chamber view, respectively. RA reference values with differentiation into males, females and all subjects, without age breakdown, and sub-division into absolute and body surface area normalized values are shown in Table 2, which have application in studies of unsorted individuals. Parameters that showed differences with age are also depicted, with age breakdown, in Table 3.

\section{Influence of body surface area on atrial parameters}

BSA was significantly higher in males than in females ( $\mathrm{p}<0.001$ ). On multivariable analysis, BSA was found to have significant independent influence on all RA parameters except on 2-chamber area, and on transverse diameter in the 2-chamber view.

\section{Influence of age on atrial parameters}

No significant increase in RA volume with age was observed in either univariable or multivariable analysis. On univariable analysis there was a significant decrease in 


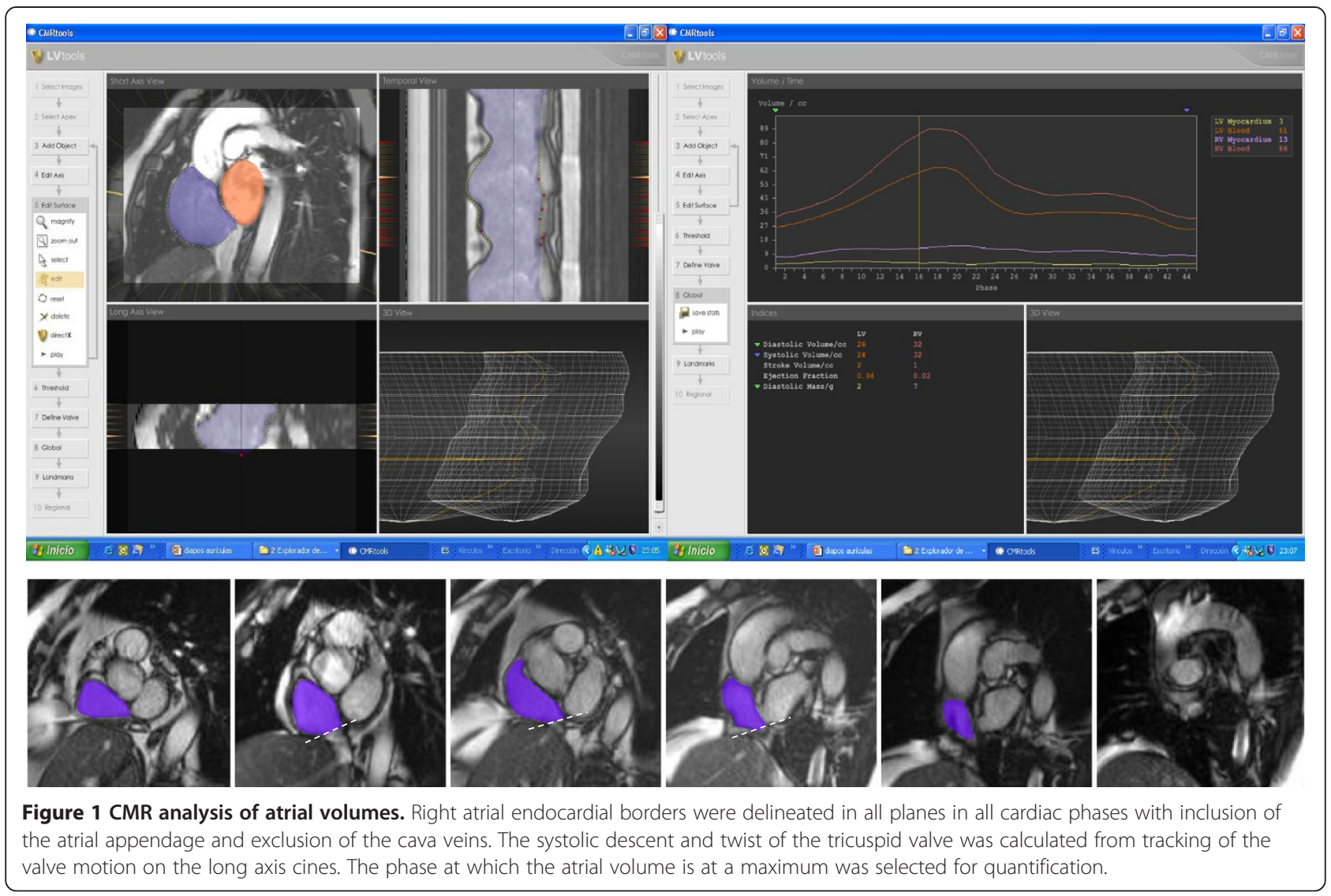

absolute and normalized areas and transverse diameters (measured in the 2-chamber view) in males $(\mathrm{p}<0.001)$, and in absolute and normalized areas in the 2-chamber view and normalized diameter in the 4-chamber view in females $(p=0.013,0.046$ and 0.043 respectively). On multivariable analysis, age was an independent predictor of absolute and normalized transverse diameters and areas (measured in the 2-chamber view) (all $\mathrm{p}=0.001$ ). Variables with significant differences according to age are depicted in Table 3.

\section{Influence of gender on atrial parameters}

All absolute right atrial volume, diameters and areas were significantly larger in males (all $\mathrm{p}<0.05$ ) except transverse diameter in the 2-chamber view. When these parameters were normalized to BSA, only longitudinal (4-chamber view), and transverse (2-chamber view) diameters showed differences, being both higher in females. On multivariable analysis, gender had no significant independent influence on any variable.

\section{Predictors of atrial enlargement in the patient group}

The baseline characteristics of the patient group are also depicted in Table 1. In this group of patients RA volumes showed a significant dispersion and, consequently, RA volume index (RAVi) ranged from 18 to $253 \mathrm{~mL} / \mathrm{m}^{2}$ (mean \pm SD $\left.59 \pm 35 \mathrm{~mL} / \mathrm{m}^{2}\right)$. According to our own normal reference values reported in Table 2, 22 patients (11 males, 11 females) had left atrial enlargement (RAVi $>78 \mathrm{~mL} / \mathrm{m}^{2}$ in males and $>70 \mathrm{~mL} / \mathrm{m}^{2}$ in females). We aimed to determine the best independent predictors of RA enlargement, for which multivariate logistic regression analysis with forward selection procedure was performed for indexed 1D and 2D parameters. For the sake of simplicity, these parameters were included as categorical dichotomous variables (below or above each parameter's upper limit of normal for all subjects). This analysis showed that the best predictors of RA enlargement were indexed area and indexed longitudinal diameter in the 2-chamber (Table 4).

\section{Estimation of right atrial volume from 2D based dimensions in the patient group}

All 1D and 2D parameters correlated significantly with RA volume. The best correlations were found for areas measured in the 2-chamber $(\mathrm{r}=0.904, \mathrm{p}<0.001)$ and 4-chamber views $(r=0.868, p<0.001)$ (Table 5). Finally, linear regression analysis was used in the patient group in order to estimate RA volume (Table 6). All nonindexed 1D and 2D measurements were included in multiple linear regression analysis and the equation obtained was: 

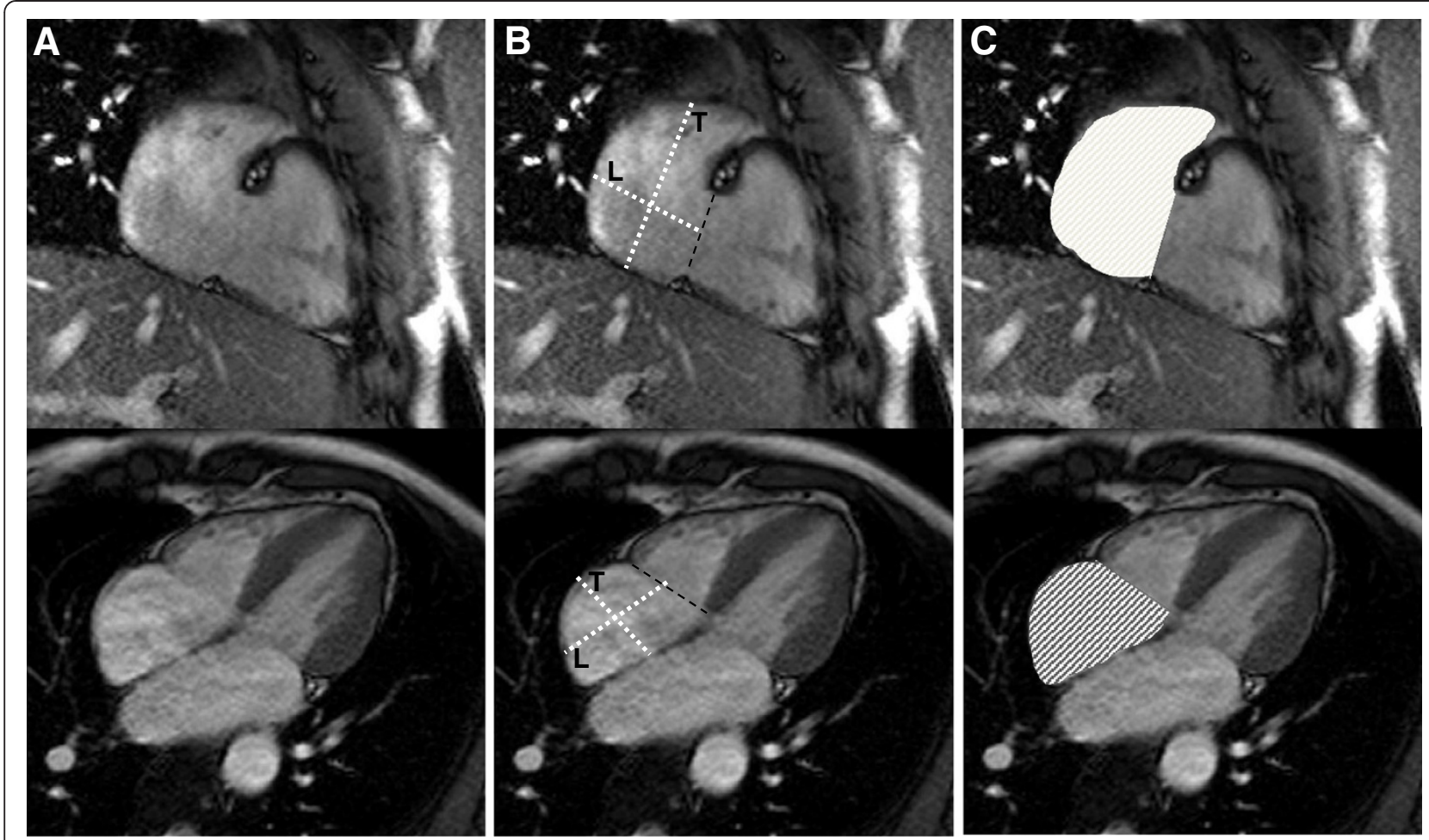

Figure 2 Measurement of right atrial parameters. Areas and diameters were measured in the phase of the cardiac cycle at which the atrial size was at a maximum. The figure shows the 2-chamber (top) and 4-chamber (bottom) views in which measurements were done. In B), longitudinal diameter $(\mathrm{L})$ is obtained from the posterior wall of the right atrium to the center of the tricuspid plane, and transverse diameter (T) is obtained perpendicular to the longitudinal diameter, at the mid level of the right atrium. In C) measured areas are shown for both views.

RA volume $=3.08 *(2 \mathrm{C}$ area $)+3.36 *(4 \mathrm{C}$ area $)-44.4$ with an $\mathrm{R}^{2}$ of 0.895 (Figure 3 ).

This method was then tested in the group of healthy subjects, and compared to the area-length method [18]. Correlation coefficient with real RA volume was $r=$ 0.824 for our method and 0.649 for the area-length method. Both methods were shown to underestimate real volume, with a mean difference of $3.38 \pm 13 \mathrm{~mL}$ for our method and $22.7 \pm 19.8 \mathrm{~mL}$ for the area-length method (Figure 4).

\section{Discussion}

Measurement of RA volume is not routinely performed clinically although its prognostic value has been shown in a number of conditions, such as chronic heart failure [5], atrial fibrillation [19] of pulmonary arterial hypertension [20]. This current study provides normal reference ranges for RA dimensions using state-of-the-art CMR acquisition techniques and analysis in a healthy moderately large population, which has been very well characterized for the absence of heart failure or any cardiomyopathy. CMR is a gold standard clinical technique to measure cardiac volumes and function, so these data have significant clinical utility. The tables of results include all RA 1D and 2D parameters and volume, and are divided into males/females or all subjects, and in age deciles, when appropriate, or all ages, in order to have applicability for comparison with any other future research data set. For all ages and genders, a volume of $139 \mathrm{~mL}\left(75 \mathrm{~mL} / \mathrm{m}^{2}\right)$ was obtained as the upper limit of normality. With regard to areas, the upper limits of normality were $30 \mathrm{~cm}^{2}\left(15 \mathrm{~cm}^{2} / \mathrm{m}^{2}\right)$ in the four chamber view, and $29 \mathrm{~cm}^{2}\left(16 \mathrm{~cm}^{2} / \mathrm{m}^{2}\right)$ in the 2-chamber. The upper limits of normality for diameters in the 4-chamber and 2-chamber views were longitudinal $6.6 \mathrm{~cm}$ $\left(3.6 \mathrm{~cm} / \mathrm{m}^{2}\right)$ and $6.5 \mathrm{~cm}\left(3.5 \mathrm{~cm} / \mathrm{m}^{2}\right)$, and transverse $5.8 \mathrm{~cm}\left(3.2 \mathrm{~cm} / \mathrm{m}^{2}\right)$ and $5.7 \mathrm{~cm}\left(3.2 \mathrm{~cm} / \mathrm{m}^{2}\right)$, respectively.

RA volume measurements with $C M R$ have been validated in the past using an excised heart cast model [21], but there is little peer-reviewed validated literature on RA reference dimensions to compare our data [12,22,23], with very different results that are partly due to differences in imaging sequences, imaging views, acquisition, analysis and characteristics of the patients included. Some authors have published reference ranges for RA dimensions with CMR but we have not found any other study in which all 1D, 2D and 3D parameters were measured with CMR. Anderson et al. [13], measured maximal RA area and depth in end-systole in the four-chamber view and obtained an upper limit of normality of $23.5 \mathrm{~cm}^{2}$ for area and $55.6 \mathrm{~mm}$ for depth, with no significant differences 
Table 2 Healthy subjects- Right atrial summary data for all ages (mean \pm SD, 95\% confidence interval)

\begin{tabular}{|c|c|c|c|}
\hline & All & Males & Females \\
\hline Volume [mL] SD 20 & $100(61,139)$ & $109(64,154)$ & $91(58,124)$ \\
\hline Volume/BSA [mL/m²] SD 10.3 & $54(34,75)$ & $55(33,78)$ & $53(36,70)$ \\
\hline Area $-4 \mathrm{ch}\left[\mathrm{cm}^{2}\right]$ SD 3.8 & $22(15,30)$ & $24(15,33)$ & $20(15,26)$ \\
\hline Area/BSA - $4 \mathrm{ch}\left[\mathrm{cm}^{2} / \mathrm{m}^{2}\right] \mathrm{SD} 1.8$ & $12(8,15)$ & $12(8,16)$ & $12(9,15)$ \\
\hline Longitudinal diameter - 4 ch [cm] SD 0.58 & $5.5(4.3,6.6)$ & $5.6(4.6,6.7)$ & $5.3(4.3,6.4)$ \\
\hline Longitudinal diameter/BSA - $4 \mathrm{ch}\left[\mathrm{cm} / \mathrm{m}^{2}\right] \mathrm{SD} 0.32$ & $3.0(2.4,3.6)$ & $2.9(2.5,3.3)$ & $3.1(2.6,3.6)$ \\
\hline Transverse diameter - $4 \mathrm{ch}[\mathrm{cm}]$ SD 0.55 & $4.7(3.7,5.8)$ & $5.0(3.7,6.4)$ & $4.5(3.6,5.4)$ \\
\hline Transverse diameter/BSA - $4 \mathrm{ch}\left[\mathrm{cm} / \mathrm{m}^{2}\right]$ SD 0.3 & $2.6(2.0,3.2)$ & $2.6(1.9,3.3)$ & $2.6(2.2,3.1)$ \\
\hline Area $-2 \mathrm{ch}\left[\mathrm{cm}^{2}\right] \mathrm{SD} 3.95^{*}$ & $22(14,29)$ & $23(14,31)$ & $21(14,27)$ \\
\hline Area/BSA - $2 \mathrm{ch}\left[\mathrm{cm}^{2} / \mathrm{m}^{2}\right] \mathrm{SD} 2.27$ * & $12(7,16)$ & $12(7,16)$ & $12(8,16)$ \\
\hline Longitudinal diameter - $2 \mathrm{ch}[\mathrm{cm}]$ SD 0.5 & $5.4(4.4,6.5)$ & $5.7(4.6,6.8)$ & $5.1(4.1,6.1)$ \\
\hline Longitudinal diameter/BSA - $2 \mathrm{ch}\left[\mathrm{cm} / \mathrm{m}^{2}\right] \mathrm{SD} 0.3$ & $2.9(2.4,3.5)$ & $2.9(2.3,3.4)$ & $3.0(2.0,4.0)$ \\
\hline Transverse diameter $-2 \mathrm{ch}[\mathrm{cm}] \mathrm{SD} 0.7^{*}$ & $4.3(3.0,5.7)$ & $4.3(3.1,5.5)$ & $4.4(3.3,5.5)$ \\
\hline Transverse diameter/BSA - $2 \mathrm{ch}\left[\mathrm{cm} / \mathrm{m}^{2}\right] \mathrm{SD} 0.4^{*}$ & $2.4(1.5,3.2)$ & $2.2(1.5,2.9)$ & $2.6(1.5,3.7)$ \\
\hline
\end{tabular}

$B S A$ - body surface area; 4 ch - 4-chamber view; 2 ch - 2-chamber view.

* Significant differences $(p<0.05)$ among age groups on multivariate analysis.

between men and women (4-chamber RA area 22.5 vs $18.8 \mathrm{~cm} 2$, RA depth 52.7 vs $51.5 \mathrm{~mm}$ ). For the sake of simplicity, these authors concluded that an area $<24 \mathrm{~cm} 2$ and a depth $<58 \mathrm{~mm}$ included the upper 95th percentile of the normal range both for the left and right atria and best separated cardiomyopathic from normal hearts, these values are slightly lower than ours. Sievers et al. [11], measured RA volumes in 70 subjects using the short axis method and published an upper limit of normality of RA volume of $170.4 \mathrm{~mL}(89.2 \mathrm{~mL} / \mathrm{m} 2)$, which is higher than our results. We think that this difference in the upper limit of normality is attributable to a different, more heterogeneous, subject population, as both the imaging sequence, acquisition method- with retrospective gating- and image analysis were similar to ours. In fact the mean RA volume in Sievers's study is $101 \mathrm{~mL}$ with a standard deviation of $30.2 \mathrm{~mL}$, while we found a very similar RA volume, of $100 \mathrm{~mL}$, with a lower standard deviation, $20 \mathrm{~mL}$, and thus a narrower normal range and lower upper limit.

Table 3 Healthy subjects- Right atrial parameters with significant differences with age on multivariate analysis (mean, 95\% confidence interval)

\begin{tabular}{|c|c|c|c|c|c|c|}
\hline & $20-29$ years & 30-39 years & $40-49$ years & $50-59$ years & $60-69$ years & $70-79$ years \\
\hline & \multicolumn{6}{|c|}{ All subjects } \\
\hline RA area-2 ch $\left[\mathrm{cm}^{2}\right]$ SD 4.5 & $24(16,32)$ & $23(15,31)$ & $22(14,30)$ & $21(13,29)$ & $20(12,28)$ & $19(11,27)$ \\
\hline RA area/BSA- $2 \mathrm{ch}\left[\mathrm{cm}^{2} / \mathrm{m}^{2}\right]$ SD 2.5 & $13(9,18)$ & $13(8,17)$ & $12(8,17)$ & $12(7,16)$ & $11(6,15)$ & $10(6,15)$ \\
\hline RA transverse diameter- $2 \mathrm{ch}[\mathrm{cm}] \mathrm{SD} 0.6$ & $5.1(3.7,6.4)$ & $4.7(3.4,6.1)$ & $4.4(3.1,5.8)$ & $4.1(2.8,5.5)$ & $3.8(2.5,5.2)$ & $3.5(2.1,4.8)$ \\
\hline \multirow[t]{2}{*}{ RA transverse diameter/BSA- $2 \mathrm{ch}\left[\mathrm{cm} / \mathrm{m}^{2}\right] \mathrm{SD} 0.4$} & $2.8(2.1,3.6)$ & $2.7(1.8,3.5)$ & $2.5(1.6,3.4)$ & $2.3(1.4,3.2)$ & $2.2(1.3,3.1)$ & $2.0(1.1,2.9)$ \\
\hline & \multicolumn{6}{|c|}{ Males } \\
\hline RA area-2 ch $\left[\mathrm{cm}^{2}\right]$ SD 4.5 & $25(16,33)$ & $24(15,33)$ & $23(14,32)$ & $22(14,31)$ & $21(13,30)$ & $21(12,29)$ \\
\hline RA area/BSA- $2 \mathrm{ch}\left[\mathrm{cm}^{2} / \mathrm{m}^{2}\right]$ SD 2.5 & $13(8,17)$ & $12(8,17)$ & $12(7,17)$ & $11(7,16)$ & $11(6,16)$ & $10(6,15)$ \\
\hline RA transverse diameter- $2 \mathrm{ch}[\mathrm{cm}] \mathrm{SD} 0.6$ & $4.9(3.7,6.2)$ & $4.7(3.5,6.0)$ & $4.5(3.3,5.7)$ & $4.2(3.0,5.4)$ & $4.0(2.8,5.2)$ & $3.7(2.5,4.9)$ \\
\hline \multirow[t]{2}{*}{ RA transverse diameter/BSA- $2 \mathrm{ch}\left[\mathrm{cm} / \mathrm{m}^{2}\right] \mathrm{SD} 0.4$} & $2.5(1.8,3.2)$ & $2.4(1.7,3.1)$ & $2.3(1.6,3.0)$ & $2.1(1.4,2.8)$ & $2.0(1.3,2.7)$ & $1.9(1.2,2.6)$ \\
\hline & \multicolumn{6}{|c|}{ Females } \\
\hline RA area-2 ch $\left[\mathrm{cm}^{2}\right]$ SD 3.4 & $24(17,31)$ & $23(16,29)$ & $21(15,28)$ & $20(13,27)$ & $19(12,25)$ & $18(11,24)$ \\
\hline RA area/BSA- $2 \mathrm{ch}$ view $\left[\mathrm{cm}^{2} / \mathrm{m}^{2}\right] \mathrm{SD} 2$ & $14(10,18)$ & $13(9,18)$ & $13(8,17)$ & $12(8,16)$ & $11(7,15)$ & $10(6,14)$ \\
\hline RA transverse diameter-2 ch [cm] SD 0.6 & $5.1(4.0,6.2)$ & $4.8(3.7,5.9)$ & $4.5(3.4,5.6)$ & $4.2(3.1,5.3)$ & $3.9(2.8,5.0)$ & $3.6(2.5,4.7)$ \\
\hline RA transverse diameter/BSA- $2 \mathrm{ch}\left[\mathrm{cm} / \mathrm{m}^{2}\right]$ SD 0.4 & $3.1(2.3,3.9)$ & $2.9(1.8,4.0)$ & $2.7(1.6,3.8)$ & $2.5(1.4,3.6)$ & $2.3(1.2,3.4)$ & $2.1(1.0,3.2)$ \\
\hline
\end{tabular}

$L A$ - left atrium; $A P$ - anteroposterior; 2ch - 2-chamber view; $R A$ - right atrium; $B S A$ - body surface area; $S D$ - standard deviation. 
Table 4 Predictors of right atrial enlargement according to RA volume index

\begin{tabular}{|c|c|c|c|c|}
\hline Univariate analysis: & OR & $95 \% \mathrm{Cl}$ & $\mathrm{p}$ value & Chi square \\
\hline 4-chamber longitudinal diameter $(>6.6 \mathrm{~cm})$ & 13.6 & $6.97,26.62$ & $<0.001$ & NA \\
\hline 4-chamber transverse diameter $(>5.8 \mathrm{~cm})$ & 5.0 & $2.41,10.37$ & $<0.001$ & 18.7 \\
\hline 4-chamber area (>30 cm2) & 17.05 & $6.99,41.17$ & $<0.001$ & 39.2 \\
\hline 2-chamber longitudinal diameter $(>6.5 \mathrm{~cm})$ & 9.6 & $4.14,22.36$ & $<0.001$ & 27.7 \\
\hline 2-chamber transverse diameter $(>5.7 \mathrm{~cm})$ & 12.1 & $4.89,30.12$ & $<0.001$ & 29 \\
\hline 2-chamber area (>29 cm2) & 21.6 & $6.83,68.14$ & $<0.001$ & 27.4 \\
\hline 4-chamber longitudinal diameter indexed $(>3.6 \mathrm{~cm} / \mathrm{m} 2)$ & 8.4 & $4.14,17.12$ & $<0.001$ & 34.5 \\
\hline 4-chamber transverse diameter indexed $(>3.2 \mathrm{~cm} / \mathrm{m} 2)$ & 8.4 & $3.29,21.45$ & $<0.001$ & 19.8 \\
\hline 4-chamber area indexed (>15 cm2/m2) & 10.8 & $4.66,25.18$ & $<0.001$ & 30.7 \\
\hline 2-chamber longitudinal diameter indexed $(>3.5 \mathrm{~cm} / \mathrm{m} 2)$ & 12.0 & $3.71,38.82$ & $<0.001$ & 17.2 \\
\hline 2-chamber transverse diameter indexed $(>3.2 \mathrm{~cm} / \mathrm{m} 2)$ & 8.7 & $3.67,20.44$ & $<0.001$ & 24.3 \\
\hline 2-chamber area indexed (>16 cm2/m2) & 38.5 & $9.55,154.82$ & $<0.001$ & 26.4 \\
\hline Multivariate analysis (indexed parameters): & OR & $95 \% \mathrm{Cl}$ & $p$ value & Chi square \\
\hline 2-chamber area indexed (>16 cm2/m2) & 6.71 & $2.35,19.13$ & $<0.001$ & 32.9 \\
\hline 2-chamber longitudinal diameter indexed $(>3.5 \mathrm{~cm} / \mathrm{m} 2)$ & 7.78 & $2.14,28.35$ & 0.002 & \\
\hline
\end{tabular}

The upper limit of normal is shown in brackets according to Table 2 .

We observed that nearly all non-indexed 1D, 2D and 3D parameters were significantly higher in males, while these differences disappeared in most indexed parameters. This is in accordance with the findings by Sievers et al. [11], who observed higher absolute volumes in males but no differences after adjusting by body surface area.

With respect to age, we found no differences in RA volume with increasing age in this group of healthy individuals, and only found significant differences in both absolute and indexed transverse diameter and area in the 2-chamber view. The RA is exposed to right ventricular diastolic pressure and, because of its thin walls, tends to dilate when pressure increases. In a healthy population this is not the case and, though with increasing age a mild degree of myocardial stiffness could be expected, no significant effect on RA volume was observed. Diastolic function parameters derived from ventricular time-volume curves in this healthy population have been published elsewhere. This has been corroborated in a post-mortem study [19], and in a number of in-vivo studies with different imaging techniques. Sievers

Table 5 Correlations of 1D and 2D parameters with RA volume (non-indexed parameters)

\begin{tabular}{lcc}
\hline Univariate analysis: & Pearson's coefficient & p value \\
\hline 4-chamber longitudinal diameter & 0.840 & $<0.001$ \\
4-chamber transverse diameter & 0.654 & $<0.001$ \\
4-chamber area & 0.868 & $<0.001$ \\
2-chamber longitudinal diameter & 0.746 & $<0.001$ \\
2-chamber transverse diameter & 0.773 & $<0.001$ \\
2-chamber area & 0.904 & $<0.001$ \\
\hline
\end{tabular}

et al. [11], observed no age related differences in RA volume with CMR. Aune et al. [24], measured RA volume by $3 \mathrm{D}$ echocardiography in 166 healthy subjects and found that normal aging does not increase RA size. On the other hand Grapsa et al. [20], studied 62 consecutive patients with pulmonary arterial hypertension and observed increased RA sphericity index, which was a good predictor of clinical outcome.

\section{Comparison with echocardiographic studies and other imaging techniques}

CMR does not require geometric assumptions to measure atrial volume, so volumes obtained with retrospectively gated CMR are likely to differ significantly from those obtained with 1D and 2D echocardiography. Echocardiographic reference values have been quoted as $4.2 \pm 0.4 \mathrm{~cm}$ for RA depth and $14.0 \pm 1.5 \mathrm{~cm}^{2}$ for RA area [25], lower than our measurements. Differences are also related to the greater precision of CMR compared with echo, the improved spatial resolution of endocardial border and slightly different anatomic views. Similarly Wang et al. [26], estimated with RA volume with the echocardiographic area length method from the apical four-chamber view and obtained an upper limit of normality of $31 \mathrm{~mL} /$ $\mathrm{m}^{2}$, far below our values, which can be explained by the different methodological approach and technical equipment. Whitlock et al. [27] compared RA volume estimated using the echocardiographic area-length method and CMR and found that echocardiography caused a significant underestimation of RA volume. Currently, 3D echo is a more reproducible and robust method for measuring RA volume. Aune et al. [24], obtained with 3D echo an 
Table 6 Predictors of right atrial volumes

\begin{tabular}{|c|c|c|c|c|}
\hline Univariate analysis: & Coeff & $95 \% \mathrm{Cl}$ & $\mathrm{p}$ value & $r$ squared \\
\hline 4-chamber longitudinal diameter $(\mathrm{cm})$ & 48.4 & $42.7,54.1$ & $<0.001$ & 0.703 \\
\hline 4-chamber transverse diameter $(\mathrm{cm})$ & 49.0 & $38.7,59.3$ & $<0.001$ & 0.428 \\
\hline 4-chamber area $(\mathrm{cm} 2)$ & 6.72 & $6.0,7.4$ & $<0.001$ & 0.752 \\
\hline 2-chamber longitudinal diameter $(\mathrm{cm})$ & 42.7 & $35.1,50.3$ & $<0.001$ & 0.556 \\
\hline 2-chamber transverse diameter $(\mathrm{cm})$ & 31.9 & $26.5,37.4$ & $<0.001$ & 0.573 \\
\hline 2-chamber area $(\mathrm{cm} 2)$ & 4.6 & $4.2,5.1$ & $<0.001$ & 0.806 \\
\hline 4-chamber longitudinal diameter indexed $(\mathrm{cm} / \mathrm{m} 2)$ & 63.7 & $52.2,75.1$ & $<0.001$ & 0.508 \\
\hline 4-chamber transverse diameter indexed $(\mathrm{cm} / \mathrm{m} 2)$ & 77.1 & $58.6,95.7$ & $<0.001$ & 0.365 \\
\hline 4-chamber area indexed (cm2/m2) & 11.1 & $9.7,12.4$ & $<0.001$ & 0.698 \\
\hline 2-chamber longitudinal diameter indexed $(\mathrm{cm} / \mathrm{m} 2)$ & 66.4 & $52.4,80.4$ & $<0.001$ & 0.470 \\
\hline 2-chamber transverse diameter indexed (cm/m2) & 51.4 & $41.4,61.3$ & $<0.001$ & 0.512 \\
\hline 2-chamber area indexed (cm2/m2) & 7.8 & $7.0,8.6$ & $<0.001$ & 0.772 \\
\hline Multivariate analysis: non-indexed measurements & Coeff & $95 \% \mathrm{Cl}$ & $p$ value & $r$ squared \\
\hline 2-chamber area $(\mathrm{cm} 2)$ & 3.1 & $2.6,3.6$ & $<0.001$ & 0.895 \\
\hline 4-chamber area $(\mathrm{cm} 2)$ & 3.4 & $2.6,4.1$ & $<0.001$ & \\
\hline Constant & -44.4 & & & \\
\hline
\end{tabular}

upper normal value of $47 \mathrm{~mL} / \mathrm{m}^{2}$ for the entire group, with a higher upper reference value for males $\left(50 \mathrm{~mL} / \mathrm{m}^{2}\right)$ than females $\left(41 \mathrm{~mL} / \mathrm{m}^{2}\right)$, still lower than our results. Noteworthy, in this 3D echo study RA volume was found to be $15 \%$ higher than normal left atrial volume, similar to our findings comparing to our previous paper on LA volumes, and no significant correlation was found between RA volume and age. Keller et al. [23], validated echo derived RA volumes against CMR and found an excellent correlation for $3 \mathrm{D}$ echo derived RA volume $(r=0.91)$, with

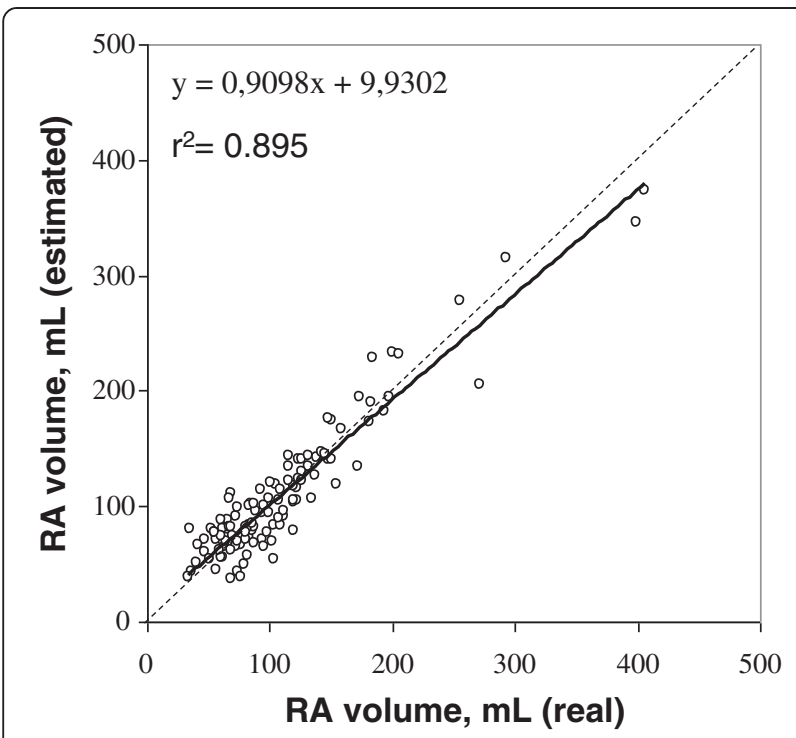

Figure 3 Scatterplot showing the correlation between real RA volume and volume estimated with our method. The dotted line is the line of identity and the solid line is the line of regression. a significant underestimation of $12.06 \mathrm{~mL}$, and worse correlation for $2 \mathrm{D}$ echo using single 4-chamber summation of disks algorithm $(r=0.79)$. This underestimation could be due to a number of reasons including the higher spatial resolution of CMR, which permits more accurate border detection and better delineation of volumes within the trabeculae, low lateral resolution of the ultrasound beam, the gain dependent nature of the boundary echoes, and the lower temporal resolution of $3 \mathrm{D}$ echo and reconstruction algorithms. These authors also suggested that CMR may overestimate RA volume by including the cava venous confluence, the appendage volume and the annular plane, in our study we included the atrial appendage but carefully excluded the cava veins, and as for the tricuspid annular plane this was carefully delineated in the endsystolic phase.

Cardiac computed tomography (CCT) has also been used to measure RA volume, with reference values higher than ours. Lin et al. [28], measured RA volume with 64-row CCT in 103 healthy normotensive nonobese volunteers and obtained a reference value of 111.9 $\pm 29 \mathrm{~mL}$ with a reference range of $54.9-168.9 \mathrm{~mL}$. This difference compared to our results could be at least in part explained by differences in the recruited subjects, as this was not a population study, $57 \%$ of subjects were male and slightly older. On the contrary, Takahashi [29] measured atrial volume with 320-slice computed tomography and semi-automated 3 dimensional segmentation technique and found a normal value of $82.1 \pm 44.1 \mathrm{~mL}$, which is smaller than our results, though in this study only 22 subjects were included and thus it is difficult to compare with our study. 


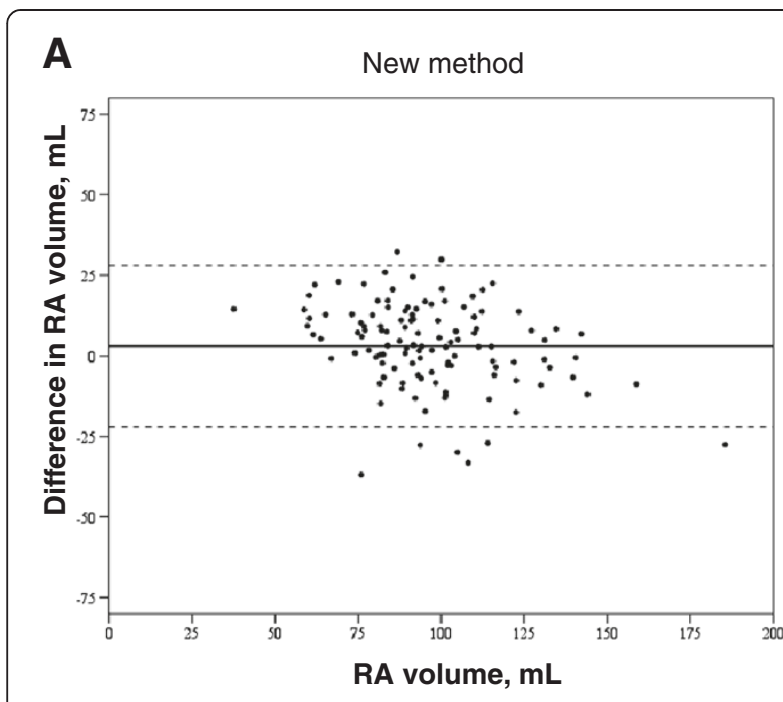

B

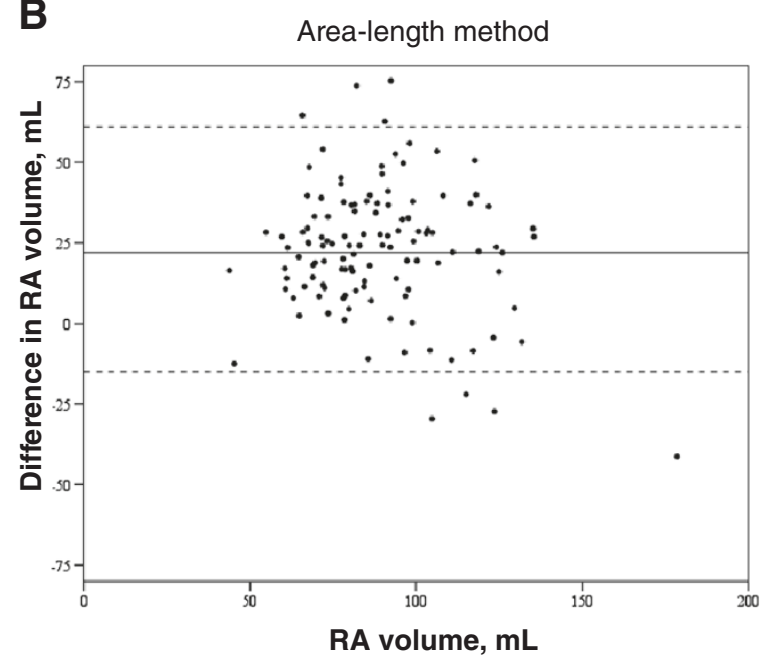

Figure 4 Bland-Altman plot. The continuous line represents the mean (bias) and the dotted lines represent the limits of agreement for $\mathbf{A}$ ) our method of RA volume estimation and $\mathbf{B}$ ) the area-length method, tested in the cohort of healthy subjects.

\section{Predictors of RA enlargement and estimators of RA volume}

Measurement of RA volume is desirable but may be timeconsuming for daily clinical practice. Therefore, 1D and $2 \mathrm{D}$ parameters might be a valuable tool to assess RA size. The best independent indicators of RA enlargement in our study were an area $>16 \mathrm{~cm}^{2} / \mathrm{m}^{2}$ and a longitudinal diameter $>3.5 \mathrm{~cm} / \mathrm{m}^{2}$ in the 2-chamber view. In the study by Anderson et al. [13], a non-indexed RA area $<24 \mathrm{~cm}^{2}$ and depth $<5.8 \mathrm{~cm}$ were the parameters that best distinguished normal from abnormal atria. We have not found any other study with which to compare our data.

With respect to RA volume estimators, we found that the best method included measurement of area in the 2 and 4-chamber views. We correlated real volume with estimated volumes derived from this method and from the traditionally used single plane area-length method. Both correlated well but caused a significant underestimation of RA volume, with worse accuracy for the arealength method (mean difference of $22.7 \pm 19.8 \mathrm{~mL}$ ). Some studies have also compared methods of volume estimation with real volumes, with different results. Sievers et al. [11], also compared the single plane area-length method with the short axis method in 70 healthy subjects and found that the former overestimated RA volume.

\section{Conclusions}

Right atrial dimensions do not vary with gender after adjustment for body surface area and only a few show differences with age. References ranges are supplied with this report in both tabular and graphical form and are of significant clinical and research utility for the interpretation of CMR studies. Also, best predictors of RA enlargement are provided.

\section{Abbreviations}

(RA): Right atrial; (CMR): Cardiovascular magnetic resonance; (SSFP): Steady state free precession; (AV): Atrioventricular.

Professor Pennell is a consultant to Siemens and a director of Cardiovascular Imaging Solutions. The other authors have no conflicts to declare. This research was supported by CORDA and the British Heart Foundation. Research support was also received from Siemens.

\section{Competing interests}

The authors declare that they have no competing interests.

\section{Authors' contributions}

AMM- Study design, subject scanning, data selection, data processing, writing manuscript. JCS- Subject recruitment, data selection, data processing. MR- Study design, statistical analysis. SKP- Study design, subject scanning. DJP-Study design, editing manuscript. All authors read and approved the final manuscript.

\section{Acknowledgements}

This research was supported by the National Institute for Health Research Cardiovascular Biomedical Research Unit of Royal Brompton Hospital and Imperial College. Support was also received from CORDA, the British Heart Foundation and Siemens.

\section{Author details}

${ }^{1}$ Cardiac Imaging Unit, ERESA, Valencia, Spain. 'Department of Cardiology, Hospital Arnau de Vilanova, Valencia, Spain. ${ }^{3}$ Medical Statistics Department, Royal Brompton Hospital, London, UK. ${ }^{4}$ Cardiovascular Magnetic Resonance Unit, Royal Brompton Hospital, Sydney Street, London SW3 6NP, United Kingdom.

Received: 4 October 2012 Accepted: 28 February 2013

Published: 8 April 2013

\section{References}

1. Sanfilippo AJ, Abascal VM, Sheehan M, Oertel LB, Harrigan P, Hughes RA, Weyman AE. Atrial enlargement as a consequence of atrial fibrillation: a prospective echocardiographic study. Circulation. 1990; 82:792-7.

2. Stiles MK, John B, Wong CX, Kuklik P, Brooks AG, Lau DH, Dimitri H, RobertsThomson KC, Wilson L, De Sciscio P, Young GD, Sanders P. Paroxysmal lone atrial fibrillation is associated with an abnormal atrial substrate: characterizing the "second factor". J Am Coll Cardiol. 2009; 53:1182-91.

3. Kalifa J, Jalife J, Zaitsev AV, Bagwe S, Warren M, Moreno J, Berenfeld O, Nattel S. Intra-atrial pressure increases rate and organization of waves 
emanating from the superior pulmonary veins during atrial fibrillation. Circulation. 2003; 108:668-71.

4. Akutsu Y, Kaneko K, Kodama Y, Suyama J, Li HL, Hamazaki Y, Tanno K, Gokan T, Kobayashi Y. Association between left and right atrial remodeling with atrial fibrillation recurrence after pulmonary vein catheter ablation in patients with paroxysmal atrial fibrillation. A Pilot Study Circ Cardiovasc Imaging. 2011; 4:524-31.

5. Sallach JA, Tang WHW, Borowski AG, Tong W, Porter T, Martin MG, Jasper SE, Shrestha K, Troughton RW, Klein AL. Right atrial volume index in chronic systolic heart failure and prognosis. J Am Coll Cardiol Img. 2009; 2:257-34.

6. Raymond RJ, Hinderliter AL, Willis PW, Ralph D, Caldwell EJ, Williams W, Ettinger NA, Hill NS, Summer WR, de Boisblanc B, Schwartz T, Koch G, Clayton LM, Jöbsis MM, Crow JW, Long W. Echocardiographic predictors of adverse outcomes in primary pulmonary hypertension. J Am Coll Cardiol. 2002; 39:1214-9.

7. Bustamante-Labarta M, Perrone S, De La Fuente RL, Stutzbach P, De La Hoz RP, Torino A, Favaloro R. Right atrial size and tricúspide regurgitation severity predict mortality or transplantation in primary pulmonary hypertension. J Am Soc Echocardiogr. 2002; 15:1160-4.

8. Maceira AM, Prasad SK, Khan M, Pennell DJ. Normalized left ventricular systolic and diastolic function by steady state free precession cardiovascular magnetic resonance. J Cardiovasc Magn Reson. 2006; 8:417-26.

9. Maceira AM, Prasad SK, Khan M, Pennell DJ. Reference right ventricular systolic and diastolic function normalized to age, gender and body surface area from steady-state free precession cardiovascular magnetic resonance. Eur Heart J. 2006; 27:2879-88.

10. Maceira AM, Cosín-Sales J, Roughton M, Prasad SK, Pennell DJ. Reference left atrial dimensions and volumes by steady state free precession cardiovascular magnetic resonance. J Cardiovasc Magn Reson. 2010; 12:65-75,

11. Sievers B, Addo M, Breuckmann F, Barkhausen J, Erbel R. Reference right atrial function determined by steady-state free precession cardiovascular magnetic resonance. J Cardiovasc Magn Reson. 2007; 9:807-14.

12. Mohiaddin RH, Hasegawa M. Measurement of atrial volumes by magnetic resonance imaging in healthy volunteers and in patients with myocardial infarction. Eur Heart J. 1995; 16:106-11.

13. Anderson $J \mathrm{~L}$, Horne BD, Pennell DJ. Atrial dimensions in health and left ventricular disease using cardiovascular magnetic resonance. J Cardiovasc Magn Reson. 2005; 7:671-5.

14. Mosteller RD. Simplified calculation of body surface area. N Engl J Med. 1987; 317:1098.

15. Joint British Cardiac Society. British hyperlipidaemia association and British hypertension society recommendations on coronary prevention. Heart. 1998; 80(Suppl 2):S1-29.

16. Maisel AS, Krishnaswamy $P$, Nowak RM, McCord J, Hollander JE, Duc $P$, Omland T, Storrow AB, Abraham WT, WU AH, Clopton P, Steg PG, Westheim A, Knudsen CW, Perez A, Kazanegra R, Herrmann HC, McCullough PA. Breathing not properly multinational study investigators. Rapid measurement of b-type natriuretic peptide in the emergency diagnosis of heart failure. N Engl J Med. 2002; 347:161-7.

17. Bland JM, Altman DG. Statistical methods of assessing agreement between methods of clinical measurements. Lancet. 1986; 1:307-10.

18. Sievers B, Kirchberg S, Addo M, Bakan A, Brandts B, Trappe HJ. Assessment of left atrial volumes in sinus rhythm and atrial fibrillation using the biplane area-length method and cardiovascular magnetic resonance imaging with TrueFISP. J Cardiovasc Magn Reson. 2004; 6:593-600.

19. Platonov PG, Mitrofanova LB, Orshanskaya V, Ho SY. Structural abnormalities in atrial walls are associated with presence and persistency of atrial fibrillation but not with age. J Am Coll Cardiol. 2011; 58:2225-32.

20. Grapsa J, Gibbs SR, Zimbarra Cabrita I, Watson GF, Pavlopoulos H, Dawson D, Gin-Sing W, Howard L, Nihoyannopoulos P. The association of clinical outcome in patients with pulmonary arterial hypertension: study with real-time three-dimensional echocardiography. Eur Heart J Cardiovasc Imaging. 2012; 13:666-73.

21. Jarvinen V, Kupari M, Hekali P, Poutanen VP. Right atrial MR imaging studies of cadaveric atrial casts and comparison with right and left atrial volumes and function in healthy subjects. Radiology. 1994; 191:137-42.

22. Matsuoka H, Hamada M, Honda T, Kobayashi T, Suzuki M, Ohtani T, Takezaki M, Abe M, Fujiwara Y, Sumimoto T. Measurement of cardiac chamber volumes by cine magnetic resonance imaging. Angiology. 1993; 44:321-7.
23. Keller AM, Gopal AS, King DL. Left and right atrial volume by freehand three-dimensional echocardiography: in vivo validation using magnetic resonance imaging. Eur J Echocardiogr. 2000; 1:55-65.

24. Aune E, Baekkevar M, Roislien J, Rodevand O, Otterstad JE. Normal reference ranges for left and right atrial volumen indexes and ejection fractions obtained with real-time three-dimensional echocardiography. Eur J Echocardiogr. 2009; 10:738-44.

25. Cheitlin MD, Armstrong WF, Aurigemma GP, Beller GA, Bierman FZ, Davis JL, Douglas PS, Faxon DP, Gillam LD, Kimball TR, Kussmaul WG, Pearlman AS, Philbrick JT, Rakowski H, Thys DM, Antman EM, Smith SC Jr, Alpert JS, Gregoratos G, Anderson JL, Hiratzka LF, Hunt SA, Fuster V, Jacobs A, Gibbons RJ, Russell RO. ACC/AHA/ASE 2003 guideline update for the clinical application of echocardiography: summary article. Circulation. 2003; 108:1142-62.

26. Wang Y, Gutman JM, Heilbron D, Wahr D, Schiller NB. Atrial volume in a normal adult population by two-dimensional echocardiography. Chest. 1984; 86:595-601.

27. Whitlock M, Garg A, Gelow J, Jacobson T, Broberg C. Comparison of left and right atrial volume by echocardiography versus cardiac magnetic resonance imaging using the area-length method. Am J Cardiol. 2012; 106:1345-50.

28. Lin FY, Devereux RB, Roman MJ, Meng J, Jow VM, Jacobs A, Weinsaft JW, Shaw L, Berman DS, Callister TQ, Min JK. Cardiac chamber volumes, function and mass as determined by 64-multidetector row computed tomography: mean values among healthy adults free of hypertension and obesity. JACC Cardiovasc Imaging. 2008; 1:782-6.

29. Takahashi A, Funabashi N, Kataoka A, Yajima R, Takahashi M, Uehara M, Takaoka H, Saito M, Yamaguchi C, Lee K, Komuro I, Nomura F. Quantitative evaluation of right atrial volume and right atrial emptying fraction by 320-slice computed tomography compared with three-dimensional echocardiography. Int J Cardiol. 2011; 146:96-9.

\section{doi:10.1186/1532-429X-15-29}

Cite this article as: Maceira et al:: Reference right atrial dimensions and volume estimation by steady state free precession cardiovascular magnetic resonance. Journal of Cardiovascular Magnetic Resonance 2013 15:29.

\section{Submit your next manuscript to BioMed Central and take full advantage of:}

- Convenient online submission

- Thorough peer review

- No space constraints or color figure charges

- Immediate publication on acceptance

- Inclusion in PubMed, CAS, Scopus and Google Scholar

- Research which is freely available for redistribution 